\title{
Classification of Optokinetic After-Nystagmus (OKAN) and Its Topical-Diagnostic Significance in Humans
}

\author{
Eiji Sakata, Akinori Itoh, Kyoko Ohtsu \\ Hiroe Nohara, Mayumi Endo \\ Department of Neurotology, Saitama Medical School
}

\begin{abstract}
Optokinetic after-nystagmus (OKAN), which is often neglected today, is based on various pathological eye movements and occurs roughly between spontaneous and provoked nystagmus on the one hand and experimental nystagmus on the other. OKAN is not induced through an intense stimulus like caloric or rotatory nystagmus, however, so that it is of additional clinical importance besides its usefulness in the determination of subtle differences between the two sides. In this report the reaction modes of OKAN have been classified and summarized and its clinical significance is described.
\end{abstract}

Key words: OKAN, classification, topo-diagnosis, patho-physiology

\section{CASES AND METHOD}

This study is based on the treatment of 3599 patients who complained of dizziness and disorders of balance and were treated in our clinic for 5 years or more. The results of OKAN were analyzed in patients in whom the diagnosis was based on neurotological tests and general neurological investigations, with CTscans, VAG, surgery and section used in many cases.

An Ohm-drum of the revised Jung type was used for the stimulation. The strips were rotated with angular acceleration. The angular velocity was increased with a uniform acceleration of $1 \% \mathrm{sec}^{2}$ from 0 to $70-80^{\circ} / \mathrm{sec}$. The nystagmus which occured (OKN) was recorded by ENG, with the paper moving at a speed of $1 \mathrm{~mm} / \mathrm{sec}$.

As soon as the velocity reached $70-80^{\circ} / \mathrm{sec}$, the light was suddenly switched off and the paper speed was increased to $5 \mathrm{~mm} / \mathrm{sec}$, in order to record the OKAN on the ENG. This test was carried out three times and the recording with the best induction of OKAN was evaluated as the result of the test.

\section{INVESTIGATION RESULTS}

\section{Healthy control group}

This group consisted of 24 women aged 18 to 32 Years with no history of dizziness or any disorder of balance, and in whom various tests had not revealed abnormalities of any kind. $\mathrm{O}$ $\mathrm{KN}$ and OKAN were induced in every case. In some subjects II nd and III rd phases were demonstrated, but these decreased in the course of time. The Ist phase of OKAN lasted for 17-28 seconds and the frequency of the nystagmus lay in a range between 14 and 32 beats. No marked difference between the two sides was demonstrated for OKN and OKAN.

2. Patients with nystagmus preponderance of difference between sides 
In patients with subtle differences between sides, regardless of their peripheral-vestibular or central-vestibular origin and disappearance, and also in latent spontaneous nystagmus, the liability to nystagmus can be demonstrated clearly by the OKAN-test. There are naturally certain reservations about the demonstration of such a difference between sides. This phenomenon is seen in lateralized diseases of both central and peripheral type.

3. Disinhibitory nystagmus

The Ist phase of OKAN is short on the right and the left with no differerence between the sides. The IInd phase continues in an unlimited way into a hyperreaction, probably because of the disinhibitory impulse from the vestibulo-cerebellum to the vestibulooculomotor system. Such disinhibitory function is frequently observed in those with a median lesion.

4. Inversion type

Figure 1 shows OKAN in a 47-year-old patient with positional vertigo of the benign paroxysmal type. When OKN of the upper line was induced to the right, OKAN took a course to the left. When OKAN of the lower line was induced to the left, this took a course to the right, so that complete inversion was displayed. Such inversion of OKAN is seen in bilateral peripheral or central lesions of similar extent.

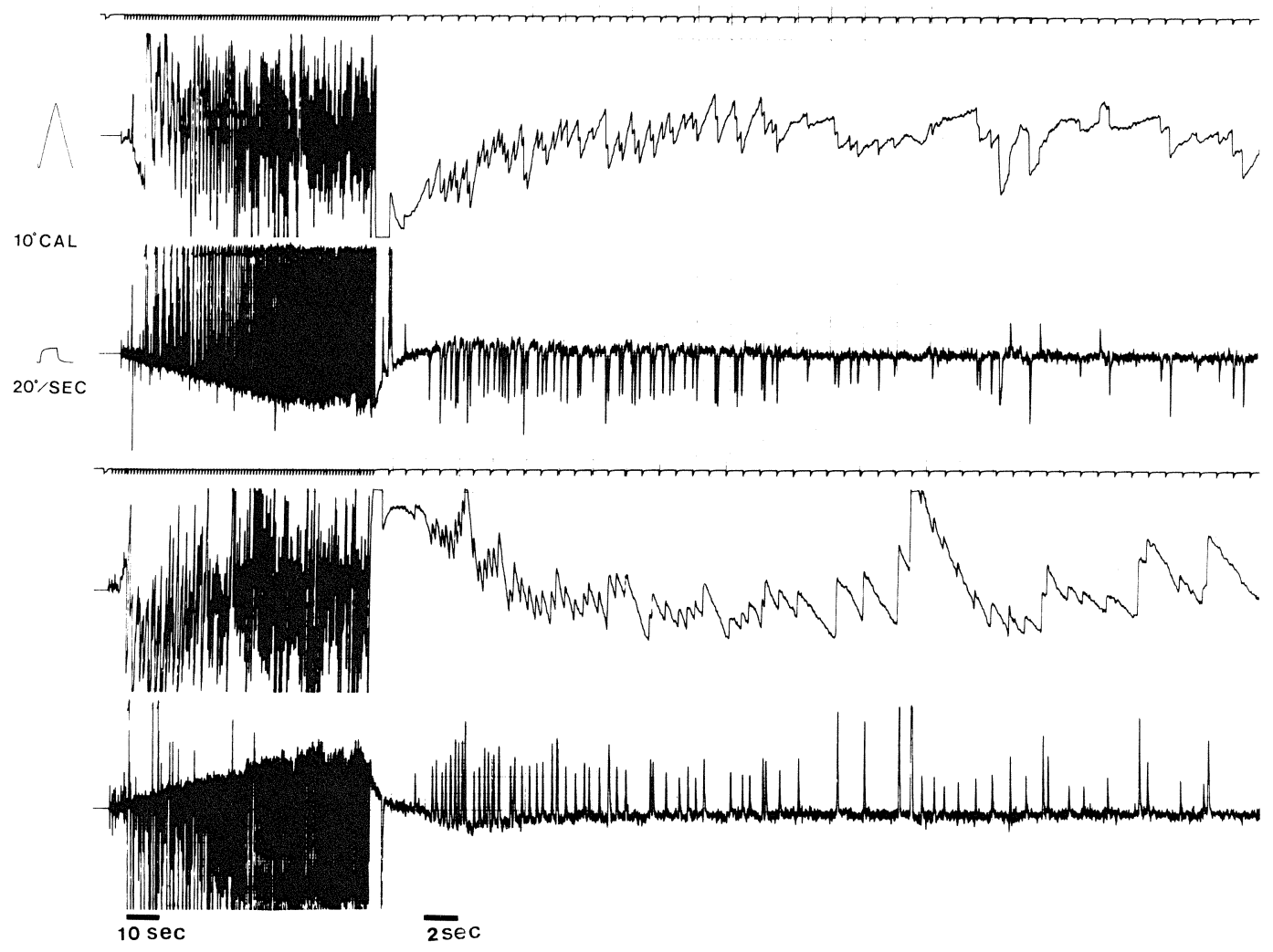

Fig. 1 Inversion of OKAN

OKAN in a 47-year-old patient with positional vertigo of the benign paroxysmal type. When OKN of the upper line was induced to the right, OKAN took a course to the left. When OKAN of the lower line was induced to the left, this took a course to the right, so that a complete inversion was displayed. 


\section{Inhibitory type}

Like the inversion type described above, this type is also seen only in bilateral vestibular disorders. Several differences are seen in the clinical and pathophysiological features however.

6. Type with dysmetric ocular movements

Fine movements, such as square wave jerks, stepped jerks and fixation jerks generally make it difficult to distinguish between the symptoms encountered in healthy subjects and in atactic patients.

In such cases the OKAN test indicates a pathological reaction on the basis of an exaggeration of the response. In contrast to this, in normal subjects generally only a slight reaction with no exaggeration is demonstrated.

7. Type with the induction of clonic spasms

As in the dysmetric type described above, ocular movements of lightning rapidity and opsoclonus may be unequivocal or improved after the phase of distinct movement, which makes the diagnosis difficult.

\section{DISCUSSION}

Most of the reports on OKAN are experimental investigations, and one is surprised by the small number of clinical studies.

In the experimental investigations, it is often found that unilateral destruction of labyrinthine function induces a reduction in or disappearance of OKAN directed towards the diseased side, whilst bilateral destruction leads to the complete disappearance of OKAN. Destruction of the lateral vestibular nuclei similarly leads to inhibition of OKAN, and, according to the reports, the intensity of horizontal OKAN seems to be closely related to the activity of the $\mathrm{Nu}$ cleus vestibulari ${ }^{\left.1{ }^{12}\right)}$. This demonstrates the influence of the peripheral vestibulum, including the Nucleus vestibularis, on the induction of OKAN. Hyperreactions of OKAN are similarly reported in patients with lesions of the vermis of the cerebellum ${ }^{3)}$.

On the other hand, the number of clinical studies of OKAN is unexpectedly small. Since the first report by Bárány ${ }^{1)}$, there have been several clinical reports, and these probably led to the experimental investigations which were subsequently carried out. To date a great many theories have been put forward about the mechanism of induction of OKAN. According to one of these theories, the central aftersound induced by OKN-stimulation is responsible for this ${ }^{2}$. Another theory claims that the nystagmus itself persists after the interruption of OKAN, which is based on the selfregulating mechanism and is in no way related to OKN-stimulation. According to a third theory, OKAN, like rotatory-after-nystagmus, is also induced by the optic-vestibular integration system in the upper brainstem. In addition rhythmic ocular movements are induced by the after-discharge of nerve cells in

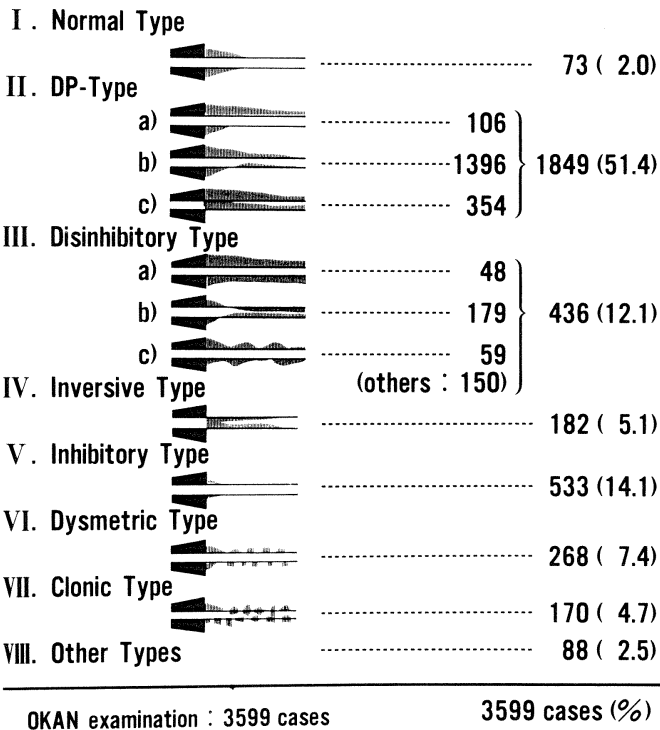

Fig. 2 Classification of OKAN-Pattern 
the pontine median reticular formation (PPRF), which is to be found in the pons in many patients $\mathrm{s}^{3 / 4)}$.

This report is based on the results of repeated examinations of 3599 patients first reported in 1970, with the addition of more recent findings. As shown in Figure 2, OKAN reactions can be classified into 7 different types. This procedure not only helps in the determination of fine vestibular differences between sides but it also contributes to the diagnosis of various kinds of lesions in and around the posterior cranial fossa.

The type with differences between the sides (II) can be further subdivided into (a) a simple difference between sides for the duration of OKAN, (b) alternation of OKAN from the diseased side to the healthy side in the Ist phase, and (c) direction of OKAN from the diseased side to the healthy side in the Ist phase. In the disinhibitory type (III) a further sub-division is possible into (a) unlimited persistence of the reaction without any marked difference between the sides, (b) semi, contralateral inversion of OKAN towards the side where it is most frequently found, followed by unlimited persistence or occasional potentiation of the reaction and provocation, (c) direction of OKAN from the healthy side from the outset onwards with exaggeration and provocation, and (d) exaggeration of the II nd phase.

The inversion type (IV) described above with a clinical example of bilateral OKAN in the opposite direction to the OKN of the Ist phase is of great clinical importance.

In Type $\mathrm{V}$, despite favourable induction of OKAN, OKN is inhibited bilaterally. This type is often encountered in patients with circulatory disorders in the brain-stem region. The clinical significance of Type VI, the type with the induction of dysmetric ocular movements, and also of Type VII, the type with the induction of clonic ocular movements, is also considerable.

\section{CONCLUSIONS}

The types of OKAN reaction have been classified into 7 types in connection with the diagnostic significance of the OKAN test and the clinical importance of each type has been defined.

The results of this reaction are subject to marked individual fluctuations and they are also influenced by various external factors such as noise, light and pain. The test conditions should therefore be examined in detail and the results assessed with careful attention being paid to these factors.

It is expected that the OKAN test will be used more widely as one of the tests of balance in the future.

\section{ABSTRACT}

1) Bárány $R$ : Physiologie und Pathologie des Bongengansapparates beim Menschen. pp 107-142, Franz Deuticke, Leipzig and Vienna, 1907

2) Brandt T, Dichgans J, Büchele W : Motion habituation: inverted self-motion perception and optokinetic after-nystagmus.

Exp. Brain Res 21 : 337-352, 1979

3 ) Sakata E, Nagashima C : Diagnostic evaluation of optokinetic after-nystagmus (O
KAN). Otolaryngol (Tokyo) 42 : 589-596, 1970

4) Itoh A, Ohtsu K, Sakata E : Diagnostic contribution of optokinetic after nystagmus (OKAN). Eguilibrium Res 43 : 243255, 1984

$\left(\begin{array}{l}\text { 原稿到着: 平成 } 5 \text { 年 } 6 \text { 月 } 28 \text { 日 } \\ \text { 別刷請求先 : 坂田英治 } \\ \text { 于350-04 埼玉県入間郡毛呂山町毛呂本郷 } 38 \\ \text { 埼玉医科大学平衡神経科学教室 }\end{array}\right)$ 